\title{
Aroma profile of pilot plant-scale produced fruit vinegar using a thermo- tolerant Acetobacter pasteurianus strain isolated from Moroccan cactus
}

\author{
Majid Mounir, ${ }^{1,2}$ Marie-Laure Fauconnier, ${ }^{3}$ Mohamed Afechtal, ${ }^{4}$ Philippe Thonart, ${ }^{2}$ \\ Mustapha Ismaili Alaoui, ${ }^{1}$ Frank Delvigne ${ }^{2}$
}

${ }^{I}$ Department of Food Science and Nutrition, Hassan II Institute of Agronomy and Veterinary Medicine, Rabat, Morocco; ${ }^{2}$ Microbial Processes and Interactions, Gembloux Agro-Bio Tech, University of Liège, Gembloux, Belgium; ${ }^{3}$ General and Organic Chemistry Unit, Gembloux AgroBio Tech, University of Liège, Gembloux, Belgium; ${ }^{4}$ National Institute for Agricultural Research (INRA), Regional Center of Kenitra, Laboratory of Virology, Kenitra, Morocco

\begin{abstract}
In this study, new thermotolerant Acetobacter pasteurianus CV01 strain recently isolated from local product of Morocco has
\end{abstract}

\footnotetext{
Correspondence: Mounir Majid, Hassan II Institute of Agronomy and Veterinary Medicine (IAV), PO Box 6202, Rabat, Morocco.

Tel.: +212.663.736.975 - Fax: +212.537.775.845.

E-mail: mounirmajid@gmail.com
}

Key words: Vinegar; SPME; thermotolerant; pilot plant-bioreactor; Acetobacter; aroma.

Acknowledgments: the authors would like to thank the Belgian Development Agency for its financial support via the scholarship granted to M. Mounir to conduct this research.

Funding: the work was supported by the Belgian Development Agency (grant, no. 12MOR/0113).

Contributions: MM carried out the experiments, wrote the manuscript and designed the figures with support from MA; M-LF designed and aided in performing solid phase microextraction analysis. She also helped in interpreting the results and worked on the manuscript; MM and MIA conceived the original idea; PT, MIA and FD conceived the study and were in charge of overall direction and planning; MA processed the experimental data and performed the data analysis. All authors discussed the results and contributed to the final version of the manuscript.

Conflict of tnterest: the authors declare that they have no potential conflict of interest.

Conference presentation: part of this paper was presented at European Symposium on Biochemical Engineering Sciences (ESBES) 2016, September 11-14, Dublin, Ireland.

Received for publication: 22 January 208.

Revision received: 31 March 2018.

Accepted for publication: 13 April 2018.

This work is licensed under a Creative Commons Attribution NonCommercial 4.0 License (CC BY-NC 4.0).

CCopyright M. Mounir et al., 2018

Licensee PAGEPress, Italy

Acetic Acid Bacteria 2018; 7:7312

doi:10.4081/aab.2018.7312 been investigated for its ability to perform efficient acetous fermentation at a large-scale. Firstly, the thermotolerance basis bioconversion of CV01 strain was compared to other mesophilic and thermotolerant acetic acid bacteria. Subsequently, CV01 strain was assessed for its ability to produce and tolerate high amount of acetic acid at optimal and thermal stress conditions in lab-scale bioreactor. It was found that the studied strain exhibited thermotolerant properties compared to reference strains and could withstand the increase in temperature during acetous fermentation in fermenter. Furthermore, gas chromatography-mass spectrometry (GC-MS) was used on the samples prepared with solid phase microextraction (SPME) to determine the volatile compounds of the pilot plant produced apple vinegar based on developed start-up and semi-continuous fermentation protocol. The operation strategy in the 500-L pilot plant scale acetator allowed achieving 7.3\% $(\mathrm{w} / \mathrm{v})$ of final acetic acid concentration recording high yield and acetification rate. The aroma profile of experimentally produced vinegar was found different from that of the commercial reference one. According to the literature, the results obtained show that major volatile compounds found in pilot-plant produced apple vinegar are related to good aromatic note descriptors which could have a positive impact on the organoleptic quality of industrial vinegar. Consequently, it can be concluded that CV01 Acetobacter strain is well suited for large-scale production of high quality fruit vinegar.

\section{Introduction}

Vinegar may be defined as a sour liquid consisting mainly of acetic acid and water. It is generally used as a condiment and preservative. ${ }^{1}$ It is obtained by acetous fermentation from various raw materials. Wine, cider, fruit musts, malted barley, or pure alcohol are used as substrates. ${ }^{1}$ The microorganisms involved in the elaboration of vinegars are mainly yeasts and acetic acid bacteria (AAB). The former being responsible for the alcoholic fermentation, and the latter is needed for the acetification process. ${ }^{2}$ The conversion of ethanol to acetic acid for the production of vinegar is the most well-known application of AAB strains.

The biological fruit vinegar resulting of the double fermentation process - alcoholic and acetic - has a nutritional benefit compared to synthetic vinegar since it provides, inter alia, the essential minerals and amino-acids. These are originating from the starting fruit, used for the fermentation, and from the bioconversion reactions. In addition, it has been proved that vinegar has a significant 
therapeutic activities used in traditional medicine. ${ }^{3}$ Industrially, the typical operation mode in submerged cultures is the semi-continuous one. ${ }^{4}$ Once the desired acidity is reached by the first fermentation cycle, a percentage of the working volume of the bioreactor is discharged and then replaced by an identical volume of the fresh fermenting medium to begin a new cycle. ${ }^{5}$

According to the literature, the final aroma and organoleptic qualities of vinegars depend essentially on the raw material employed and on the fermentation process used. ${ }^{6-8}$ The flavor or aroma is certainly one of the most determinants of food quality and acceptance of commercial vinegar. ${ }^{8}$ Indeed, the aroma profile of vinegar is the result of high quantities of distinguishing volatile compounds including acetic acid. ${ }^{9}$ The aroma compounds in fruit vinegars have interested many researchers over the past 30 years. However, less information is available on the aroma chemistry of apple cider vinegar. ${ }^{10}$

The strategies to measure odor compounds in vinegars can be divided into three main types; sensory analysis, chemical analysis, and electronic nose. Although the most popular chemical analysis method for vinegars is gas chromatography-mass spectrometry (GC-MS). ${ }^{11}$ The solid-phase micro-extraction/gas chromatography-mass spectrometry (SPME/GC-MS) provide more distinct patterns on their volatile compounds, which might be a potential tool in determining the volatile profiles of vinegars. ${ }^{8,12}$ Moreover, odor-active compounds can be analysed by chromatography-olfactometry $(\mathrm{GC}-\mathrm{O}) .^{13}$

Morocco has a rich tradition in biotechnology. Many traditional foods of animal and vegetable origin are still widely consumed and highly appreciated. ${ }^{14}$ As a consequence of the implementation of the Green Morocco Plan, the request of regional products and their derivatives is clearly increasing during the last decade. Indeed, the Moroccan consumer becomes aware of what he eats with regard to the health safety, and claims more and more for high quality products that meet sanitary and environmental standards.

From another point of view, apple vinegar remains alongside other fruit vinegars (dates, cactus, etc.) the best known type of traditional fruit vinegar in Morocco. Until nowadays, vinegar is often produced traditionally through spontaneous fermentation processes conducted in most cases on degraded fruit, and resulting in a final product that may present a risk to the consumer. FernándezCruz et al. had shown that such spontaneous fermentation process may be associated with a production of mycotoxins. ${ }^{15}$ The presence of these compounds in food is of high concern for human health due to their properties to induce severe toxicity effects at low dose levels.

The cultivation of apple fruit in Morocco is of a significant socio-economic interest with an area of around 27,000 ha. ${ }^{16}$ According to Moroccan Ministry of Agriculture and Maritime Fisheries (2014), the annual average of the production of apple fruit is estimated at 500,000 tons/year. However, the orchards are generally conducted with a limited number of cultivars which include Golden Delicious as one of the most important varieties with respect to commercial perspective. ${ }^{16}$ Industrial processing of low commercial quality apples to vinegar could contribute significantly to the development of foods with high added value in the local market. On the other hand, dates and cactus constitute another field that can be transformed by biotechnological techniques. Furthermore, 20 to $30 \%$ of annual production of these products does not fit with quality standards since they are damaged by insects or have a commercial quality failures. This situation brings down the farmers' incomes and their standards of living since in the best cases, this category of substandard foods is used as livestock feed. ${ }^{17}$ The valuation of these low-quality fruits is therefore essential.
During acetous fermentation, AAB are facing different potentially harmful environmental stress factors (temperature, $\mathrm{pH}$, concentration of acetic acid and ethanol, etc.). ${ }^{18}$ Therefore, the selection of thermotolerant $\mathrm{AAB}$ strains performing efficient oxidative fermentation could be appropriate for vinegar production in hot countries like Morocco due to the reduction of cooling water expenses.

The first part of the present study aimed to evaluate the ability of CV01 Acetobacter pasteurianus strain, isolated from Moroccan cactus to perform acetous fermentation in a pilot plant-scale bioreactor. This strain was selected for its thermotolerant properties and for its high acetic acid production capacity. ${ }^{19}$ On the other hand, this study aimed also to perform a comparative chemical and sensory analysis between the produced vinegar (using selected strains in pilot plant-scale bioreactor) and common ones manufactured in a traditional manner available in local market. For this purpose, Headspace solid-phase micro-extraction (HS-SPME) technique was used for analyzing aromatic compounds in vinegars. ${ }^{12}$

\section{Materials and Methods}

\section{Microorganisms, culture media and samples}

The yeast strain used to perform alcoholic fermentation throughout this work was Saccharomyces cerevisiae YS-DN1. This strain was isolated from Bouslikhene date cultivar (South East of Morocco) and extensively studied in an earlier work. ${ }^{20}$ On the other hand, AF01 and CV01 AAB strains, which were isolated from apple and cactus fruits, respectively in a previous study, ${ }^{19}$ were used to catalyze oxidative fermentation on alcoholic fruit musts. The two bacteria were confirmed to be closely related to $A$. pasteurianus species. ${ }^{19}$

The selected AAB strains were studied based on thermotolerance properties by comparison to other thermotolerant and mesophilic AAB. The wild-type strains used in comparative study were obtained from the Laboratory of Microbiology of Gent (Belgium) (A. senegalensis LMG 23690 ${ }^{\mathrm{T}}$ A. pasteurianus LMG 1632 and LMG 1607, and $A$. cerevisiae LMG 1625).

A modified yeast extract-peptone-dextrose (YPD) medium was used for the cultivation and maintenance of the $S$. cerevisiae cultures. It was consisted $(\mathrm{g} / \mathrm{L})$ of yeast extract, 5; peptone, 10; glucose, 20; and agar, 20. While for AAB strains, they were subcultured in GYEA medium composed of $20 \mathrm{~g} / \mathrm{L}$ glucose, $5 \mathrm{~g} / \mathrm{L}$ yeast extract, 3\% (w/v) ethanol, $1 \%(\mathrm{w} / \mathrm{v})$ acetic acid, $0.5 \mathrm{~g} / \mathrm{L}$ $\mathrm{MgSO}_{4}, 1 \mathrm{~g} / \mathrm{L} \mathrm{K}_{2} \mathrm{HPO}_{4}, 1 \mathrm{~g} / \mathrm{L}\left(\mathrm{NH}_{4}\right)_{2} \mathrm{HPO}_{4}$ and $15 \mathrm{~g} / \mathrm{L}$ agar. ${ }^{19}$ For long-term preservation of cells, the grown colonies were harvested in $40 \%$ glycerol and subsequently stored in cryovials at $-80^{\circ} \mathrm{C}$.

Vinegar samples of different sources (apple and date), representing the common types of available vinegars, were purchased from retail trade in different regions of Morocco. These samples were collected so that to perform a comparative sensory analysis with the experimentally produced vinegar using selected strains.

\section{Plant material and juice preparation}

The fruit juice on which the experiment was carried out was obtained from apple fruit (Malus domestica) of the Golden Delicious variety procured in Midelt (Middle Atlas of Morocco). The choice has been made on small size and fresh seasonal fruit (5$7 \mathrm{~cm}$ diameter) so as to facilitate the mashing. Apples were harvested from production site and processed directly to prevent alteration.

Thus, $750.5 \mathrm{~kg}$ of the Golden Delicious apple variety were recovered during the picking season (September-October) and 
transported immediately to the laboratory. It is noteworthy to mention that apples are highly perishable because of their water and sugar content, and need to be processed very quickly. ${ }^{20,21}$ This is essential to prevent the growth of pathogenic microorganisms and to ensure a final product of high quality. Therefore, apples were first cleaned up by removing the leaves, branches and any foreign matter, and then they were washed by tape water and drained on a grid dripping. The mashing process was performed using a stainless steel electric grinder. The crushed is then pressed using a hydraulic press using wooden grids and a micro-porous fabric that blocks the cake while letting the juice pass through.

Bouslikhene variety (Errachidia, Morocco) were used for the preparation of date juice. The preparation was carried out according to dipping method inspired from Nancib et al. (2001). The extraction has been performed at $65^{\circ} \mathrm{C}$ for a total duration of $2 \mathrm{~h} .{ }^{22}$ Once the dates were washed, pitted and cut, 3 liters of distilled water were added for each kilogram of dates weighed. The datewater mixture was maintained, with continuous stirring, at the treatment temperature using a water bath. The mixture was then filtered through a filter cloth to obtain clear juice.

The obtained juice samples were then placed in 120 liters plastic barrels and cold stored at $4{ }^{\circ} \mathrm{C}$. Samples were subjected to analysis of total and reducing sugars, $\mathrm{pH}$ and $\mathrm{Bx}^{\circ}$ content.

\section{Alcoholic fermentation}

Alcoholic fermentation was carried out in 120 L HDPE plastic barrels. The inoculum of the ethanol-producing $S$. cerevisiae YSDN1 strain was prepared from $40 \%$ glycerol cryovial seed cultures. Five $1.8 \mathrm{~mL}$ cryovial seed cultures were used to inoculate $1000 \mathrm{~mL}$ of sterile modified YPD liquid medium taken in 5L flask. Flasks were then grown on a rotary shaker at $30^{\circ} \mathrm{C}$ for $36 \mathrm{~h}$. This inoculum was used as a starter of alcoholic fermentation occurred in barrels. The barrels were closed aseptically using parafilm and the lids were equipped with a plastic pipes which allow extra gas drainage. As a general criterion, alcoholic fermentation was considered to have finished when the total sugar had been consumed $(<2 \mathrm{~g} / \mathrm{L}),{ }^{23}$ and when the ethanol concentration stops to increase. The fermentation in barrels was carried out at room temperature $\left(23 \pm 3^{\circ} \mathrm{C}\right)$ under static condition for 2 weeks in the laboratory.

\section{Evaluation of thermotolerance and bioconversion abili- ties of the selected AAB strains}

This part of the study aimed to evaluate the ability of the selected Acetobacter strains to perform acetous fermentation both at mesophilic and thermotolerant temperatures. To assess the thermotolerance ability of CV01 and AF01 strains, they were compared to other wild-type thermotolerant and mesophilic strains (see below) by measuring the production of acetic acid at increasing temperatures $\left(30,34,38\right.$ and $\left.41^{\circ} \mathrm{C}\right)$. Cultures were performed in $500 \mathrm{~mL}$ flasks containing $100 \mathrm{~mL}$ of GYEA/ $\mathrm{Mg}^{2+}$ medium. The flasks were inoculated with fresh colonies and incubated simultaneously in triplicate under agitation at different temperatures.

\section{Acetification process at high temperature}

To evaluate the ability of tested strain to withstand the increase in temperature during acetous fermentation in fermenter, CV01 was cultured in 6-L scaled bioreactor (INFORS, France) under the following conditions: temperature $30^{\circ}, \mathrm{pH} 5.5$, agitation $500 \mathrm{rpm}$, and aeration $1 \mathrm{VVM}$. The experiment was conducted for a first time keeping the temperature constant at $30^{\circ} \mathrm{C}$ (temperature control system on) and for a second time switching of the temperature control cooling system. Produced acetic acid and residual ethanol along with optical density $(540 \mathrm{~nm})$ were determined at regular intervals during fermentation.

\section{Pilot plant-scale production and start-up protocol}

The pilot plant-scale fermentation, made on fruit must, was performed in a $500 \mathrm{~L}$ pilot-plant acetifier (PASTO GILSON, France) using the selected endogenous CV01 A. pasteurianus strain. The equipment has a working volume of $300 \mathrm{~L}$ and consisted basically of a stainless steel cylinder reactor with $0.88 \mathrm{~m}$ internal diameter and $1.96 \mathrm{~m}$ height. The acetifier was provided by an integrated cooling system connected to the cylinder reactor allowing; i) the circulation of the outlet gas stream containing the most volatile compound into the fermenter, and ii) control of the optimum temperature of operation $\left(30-31^{\circ} \mathrm{C}\right),{ }^{24}$ settled by an internal heat exchanger connected to the cooling system. The aeration was settled at $20 \mathrm{~L} / \mathrm{min}$.

The fermentation was carried out in semi-continuous type; ${ }^{4}$ each time the environment is impoverished in ethanol, new fresh medium is added into the reactor. During the fermentation, the following elements have been followed: titratable acidity, ethanol, $\mathrm{pH}$, optical density and total bacteria.

Beforehand of main fermentation carried out in $500 \mathrm{~L}$ acetifier, $5 \mathrm{~L}$ preculture was prepared in 6-L lab-scale bioreactor (INFORS, France) using juice and conditions were as described above. The preculture medium was inoculated by $36-\mathrm{h}$ cell culture grown on plates. The preculture containing active cells at their exponential phase $\left(\mathrm{OD}_{540 \mathrm{~mm}}=0.2-0.4\right)$ was then transferred aseptically to the acetifier.

The operation on the semi-continuous acetifier was initiated with a small amount of a starting culture $(60 \mathrm{~L}$ of a medium with a high number of viable cells in their exponential growth phase), then, a progressive filling-up of the reactor was carried out, up to its final working volume (Figure 1). Even though the proposed optimum values for acetic acid and ethanol concentrations in the literature are very low (10 and $6 \mathrm{~g} / \mathrm{L}$, respectively), ${ }^{25,26}$ it was more suitable to use higher concentrations of these activators-inhibitors factors in order to reproduce the usual industrial conditions. The proposed operation procedure have been designed according to the ethanol and acetic acid concentrations at the beginning and the end of every single stage concerning the start-up and the main fermentation cycles (Figure 1). The starting concentrations of acetic acid and ethanol were fixed at $5 \%(\mathrm{v} / \mathrm{v})$ and $1 \%(\mathrm{w} / \mathrm{v})$, respectively. These values were chosen based on a previous optimization of medium composition study. ${ }^{20}$

\section{Analytical methods}

- Titratable acidity was determined by titration using $0.5 \mathrm{M}$ sodium hydroxide and phenolphthalein as indicator.

- For routine measurements, the ethanol content was calculated by two ways: For values ranged from 0 to $3 \%(\mathrm{v} / \mathrm{v})$, a densimetric method (METTLER TOLEDO, France) was used after water-distillation of samples; whereas, electric ebulliometer (ALLA, France) was used to analyze samples containing over $3 \%(\mathrm{v} / \mathrm{v})$ ethanol.

- Total acetic acid content and the rest of glucose and ethanol in the fermenting must and final vinegar samples were determined by high performance liquid chromatography (HPLC) as described by Mounir et al. ${ }^{20}$ Briefly, culture samples were collected and centrifuged at 13,000 rpm for $10 \mathrm{~min}$ and the supernatants were filtered through a $0.2 \mu \mathrm{m}$ cellulose acetate membrane (Sartorius Minisart). The HPLC analyses for glucose, ethanol, acetate and gluconate were performed using an Agilent 1110 series HPLC equipped with a Supelcogel $\mathrm{C} 610 \mathrm{H}$ column preceded by a Supelguard $\mathrm{H}$ precolumn (oven temperature $40^{\circ} \mathrm{C}$ ) and a differential refraction index detector (RID, detection cell maintained at $35^{\circ} \mathrm{C}$ ). An isocratic mobile phase consisting of $0.1 \% \mathrm{H} 3 \mathrm{PO} 4$ (in MilliQ water) was used at a flow rate of $0.5 \mathrm{~mL} / \mathrm{min}$. The method 
lasted for $35 \mathrm{~min}$ at a maximum pressure of 60 bars.

- Total biomass (UFC/mL) was determined by counting in an optical microscope using double ruling Bürker chamber.

\section{Aroma profile}

A headspace solid-phase microextraction (HS-SPME) was used for analyzing aromatic compounds in produced vinegars. The objective was to highlight if was there a difference in aroma compounds composition between homemade vinegars recovered from the local market and the pilot-plant produced vinegars using selected bacteria. The extraction of aroma was performed according to procedure proposed by Natera Marìn et al. (2002) and Jo et al. (2013). ${ }^{8,12}$ Thus, for each analysis, a volume of $15 \mathrm{~mL}$ of sample (commercial or experimental) was pipetted and placed into a 50 $\mathrm{mL}$ glass vial with $6.14 \mathrm{~g}$ of $\mathrm{NaCl}$. Then, the sample was spiked with $50 \mathrm{~mL}$ of 4-methyl-2-pentanol solution (2.27 g/L in Milli-Q water containing $80 \mathrm{~g} / \mathrm{L}$ acetic acid). The vial was capped with a PTFE-faced silicone septum and placed in a thermostated stirring block for $5 \mathrm{~min}$ at $70^{\circ} \mathrm{C}$. After that, the Carboxen-polydi-methylsiloxane fiber (CAR-PDMS $75 \mathrm{~mm}$, Supelco-USA) was exposed for $60 \mathrm{~min}$ to the headspace of the sample. Thereafter, the SPME fiber was inserted into the injector of the GC-MS system (Agilent $6890, \mathrm{CA}, \mathrm{USA}$ ), and the injection was lasted $2 \mathrm{~min}$ at $250^{\circ} \mathrm{C}$.

The GC system is equipped with a DB-WAX capillary column (Agilent J\&W CP9205, CA, USA) with the following dimensions: $30 \mathrm{~m}$ length $\mathrm{x} 0.25 \mathrm{~mm}$ I.D., and $0.25 \mu \mathrm{m}$ film thickness. Helium $(1 \mathrm{~mL} / \mathrm{min})$ were used as carrier gas and the detector temperature was fixed at $250^{\circ} \mathrm{C}$. The oven temperature was programmed as follows: kept at $35^{\circ} \mathrm{C}$ for $10 \mathrm{~min}$, ramped at $5^{\circ} \mathrm{C} / \mathrm{min}$ to $100^{\circ} \mathrm{C}$, increased at $3^{\circ} \mathrm{C} / \mathrm{min}$ to $210^{\circ} \mathrm{C}$ and held for $10 \mathrm{~min}$. The MS source and quadrupole temperatures were set at 250 and $150^{\circ} \mathrm{C}$, respectively. Identification of aromatic compounds was made by matching mass spectra of unknown with those of Wiley 6.0 MS Library with a minimum of $90 \%$ of correspondence. The relative peak areas were determined in relation to that of 4-methyl-2-pentanol, the internal standard. In addition, Linear Retention Indices (LRIs) of unknown compounds were calculated in accordance with a modified Kovats method by means of retention times of adjacently eluting n-alkanes (van Den Dool \& Dec Kratz, 1963). Identification of aromatic compounds has been performed based on information available in Pherobase databases and on peerreviewed literature. ${ }^{10,27,28}$

\section{Results and Discussion}

\section{Extraction of fruit juices}

A volume of 510 liters of apple juice was obtained after pressing $750.5 \mathrm{~kg}$ of fruit performing a yield of $0.68 \mathrm{~L} / \mathrm{Kg}$. On the other hand, a quantity of $100 \mathrm{~kg}$ of dates was pressed, and a volume of juice of 231 liters were recovered with an extraction yield of $2.31 \mathrm{~L} / \mathrm{Kg}$. It is essential to point out that in the case of dates, water was added to facilitate diffusion of soluble compounds and aroma. ${ }^{29}$ Extraction was carried out at high temperature $\left(60^{\circ} \mathrm{C}\right)$, which allows a blanching of produced juice, enzymatic inactivation and destruction of the most part of pathogens and spoilage in it. The physico-chemical composition of the produced juices is given in Table 1 .

Table 1. Physico-chemical characterization of produced juices.

\begin{tabular}{lcc} 
Characteristic & Apple juice* & Date juice* \\
$\mathrm{pH}$ & $3.86 \pm 0.06$ & $5.85 \pm 0.02$ \\
Brix $(\% \mathrm{w} / \mathrm{w})$ & $13.30 \pm 0.23$ & $15.76 \pm 0.11$ \\
\hline Titratable acidity & $0.64 \pm 0.13$ & $0.36 \pm 0.09$ \\
Ash $(\% \mathrm{w} / \mathrm{w})$ & $0.22 \pm 0.05$ & $1.45 \pm 0.12$ \\
\hline Reducing sugars $(\mathrm{g} / \mathrm{L})^{\text {Total sugar }}$ & $8.2 \pm 0.97$ & $5.8 \pm 0.65$ \\
Total polyphenols $^{\S}$ & $12.2 \pm 1.45$ & $17.65 \pm 1.39$ \\
\hline
\end{tabular}

*Values are given as mean \pm standard deviation (number of repetition $=3$ ); ${ }^{\circ} \mathrm{g}$ citric acid $/ 100 \mathrm{~g} ; * \% \mathrm{~W} / \mathrm{W}$ dry matter; ${ }^{8} \mathrm{mg}$ tannic acid/100 g dry matter.

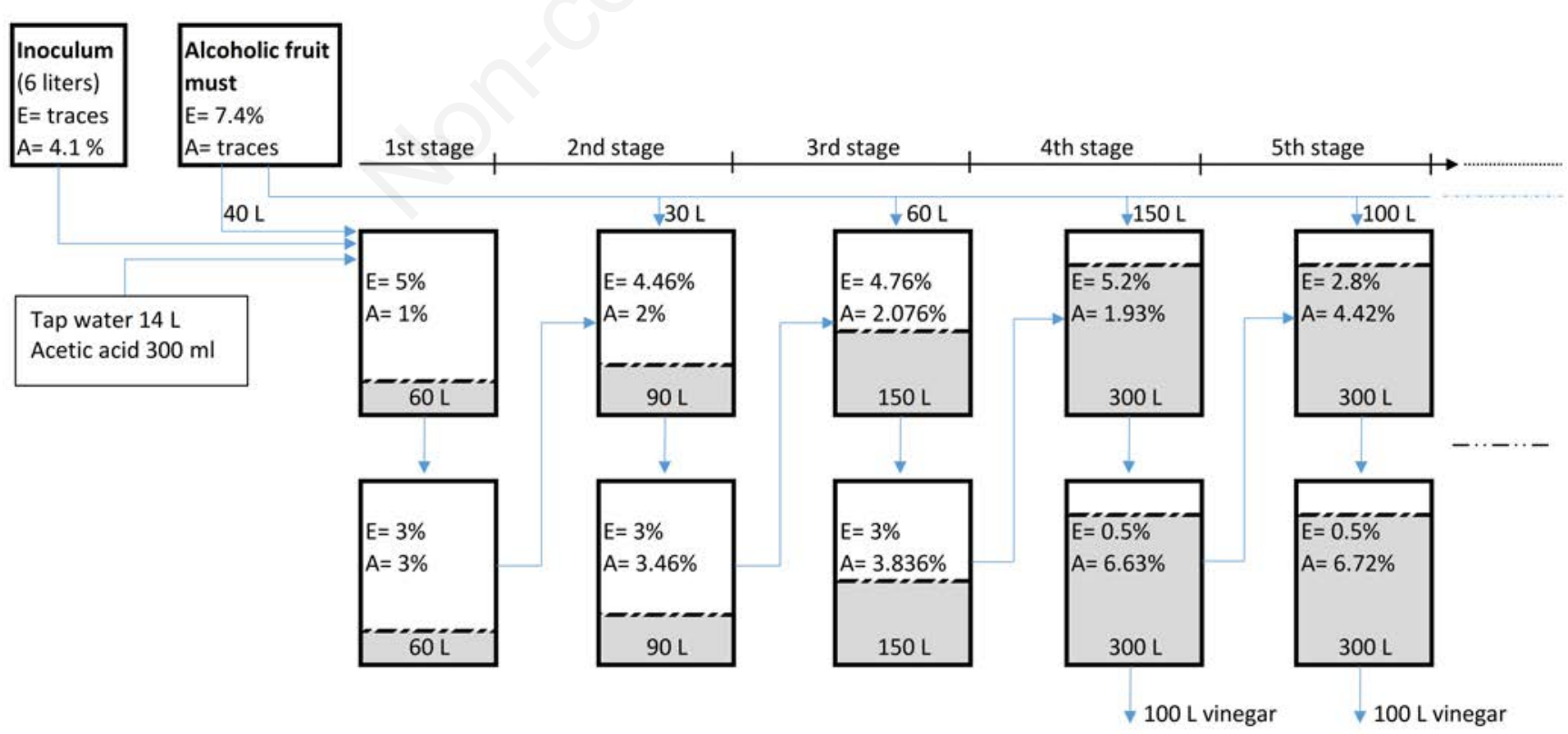

Figure 1. Start-up protocol of the $500 \mathrm{~L}$ pilot-plant acetifier. E: ethanol concentration expressed by \% (v/v); A: acetic acid concentration expressed by $\%(w / v)$. 


\section{Alcoholic fermentation}

The alcoholic fermentation was carried out in HDPE barrels at room temperature $\left(23 \pm 3^{\circ} \mathrm{C}\right)$ under static condition for 2 weeks. Physico-chemical characterization of fruit juices revealed that reducing sugars content in apple juice $(8.2 \mathrm{~g} / \mathrm{L})$ is higher compared to that in date juice $(5.8 \mathrm{~g} / \mathrm{L})$ (Table 1$)$. As a result, the final ethanol concentration obtained after 2 weeks of fermentation on apple and date juices was about $8 \% \mathrm{v} / \mathrm{v}$ and $7.8 \% \mathrm{v} / \mathrm{v}$ respectively (Figure 2). Although, as it can be seen in Figure 2, it is noteworthy to mention that $S$. cerevisiae YS-DN1 took less time to transform available fermenting sugars in the case of apple fermentation process compared to that of date one ( 8 days against 12 days for apple and date respectively) (Figure 2). This can be explained by the fact that apple juice recorded a starting $\mathrm{pH}$ of 3.86. This acidic $\mathrm{pH}$ value gives an optimal environment for the development of Saccharomyces cerevisiae.

\section{Evaluation of thermotolerance and bioconversion abili- ties of the selected AAB strains}

16S rRNA sequences of CV01 and AF01, the two Acetobacter pasteurianus strains isolated from cactus and apple vinegar, were registered in GenBank database under the accession numbers of KU710511 and KU710512 respectively. ${ }^{19,20}$ In this part of the study, these two strains were investigated for their ability to produce high amount of acetic acid at increasing temperature. Figure 3 illustrate the oxidation capacity of tested strains compared on the thermotolerance basis to wild-type mesophilic and thermotolerant
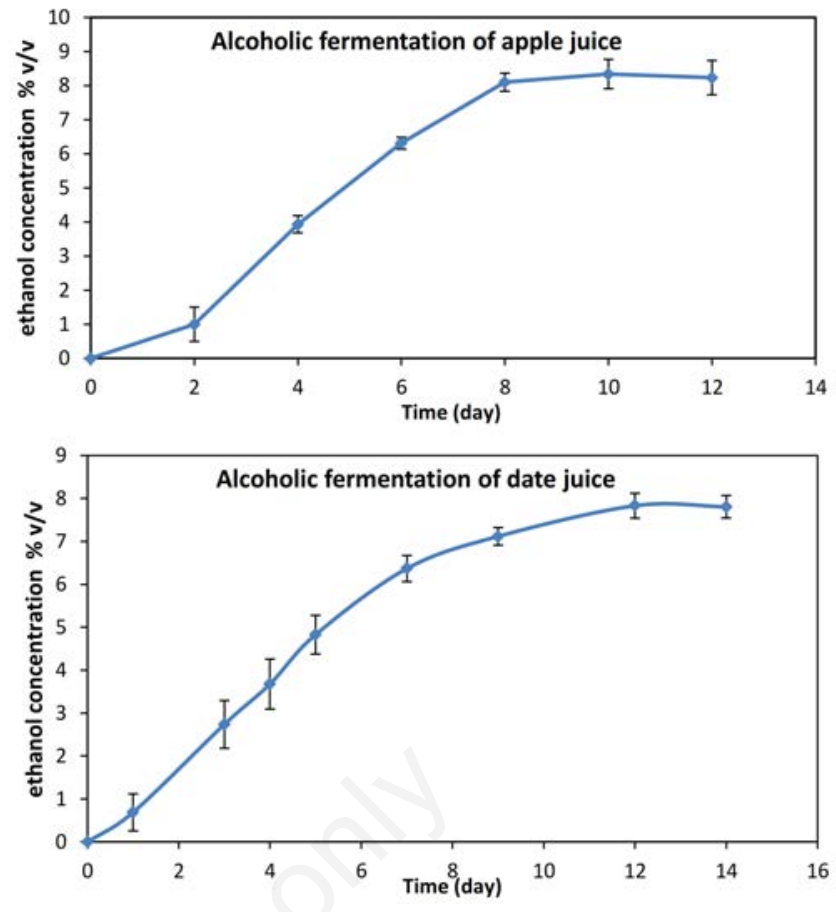

Figure 2. Produced ethanol in apple and date juices at the end of alcoholic fermentation.
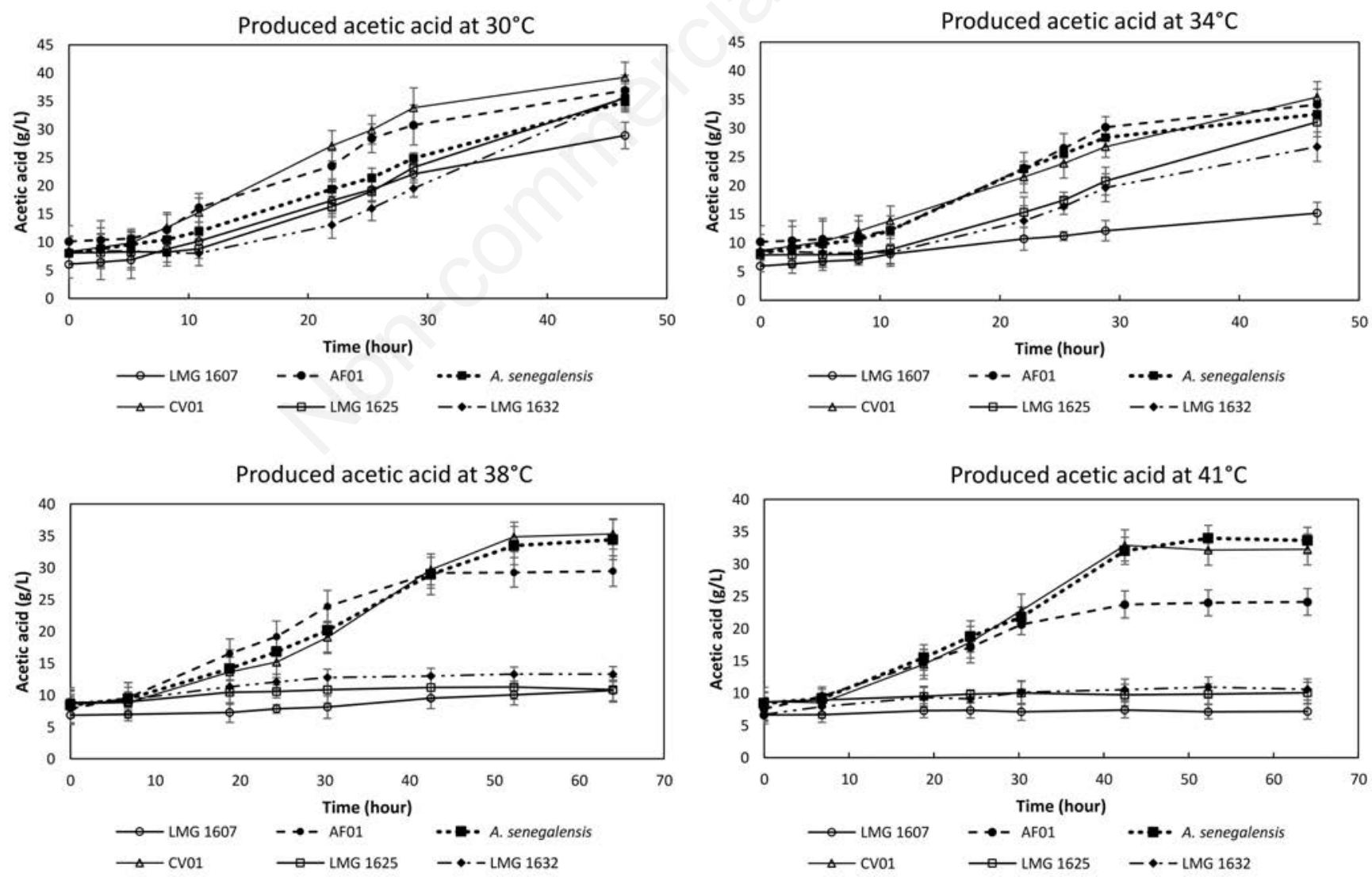

Figure 3. The variation in the experimental values of acetic acid concentrations in the medium (g/L) versus time (h) of CV01 and AF01 strains compared to A. senegalensis LMG 23690T, A. pasteurianus LMG 1632 and LMG 1607, and A. cerevisiae LMG 1625. Cultures were carried out in the same conditions at $30,34,38$ and $41^{\circ} \mathrm{C}$. 
AAB strains at a range of temperature from 30 to $41^{\circ} \mathrm{C}$.

Figure 3 shows that $\mathrm{CV} 01$ and AF01 exhibited beside $A$. senegalensis high oxidative capacity at a temperature ranging from 30 to $38^{\circ} \mathrm{C}$. At $41^{\circ} \mathrm{C}, \mathrm{CV} 01$ strain and the thermotolerant $A$. senegalensis reference strain remained the only ones that could keep good bioconversion activity with a final acetic acid concentration of around $33 \mathrm{~g} / \mathrm{L}$, while AF01 seems to be affected by temperature higher than $38^{\circ} \mathrm{C}$. In the other hand, the wild mesophilic reference strains showed an optimum bioconversion at $30^{\circ} \mathrm{C}$ and no acetate production ability was observed beyond $34^{\circ} \mathrm{C}$. The results revealed clearly that the use of CV01 strain is suited for industrial acetic fermentation at high temperature since it could grow and keep high level of acetate production under thermal stress. Consequently, optimizing the production of CV01 biomass deserves to be studied.

\section{Lab-scale acetification at high temperature}

A batch fermentation was performed for the selected thermotolerant strain CV01 in a 6 L Lab-fermenter (INFORS, France) in order to evaluate its ability to cope with the increase in temperature caused by heat release during fermentation. Figure 4 shows the batch profile of CV01 Acetobacter strain in a lab-bioreactor keeping the temperature constant at $30^{\circ} \mathrm{C}$ (Figure 4A) and switching-of the temperature control cooling system (Figure 4B). The variation of experimental values of produced biomass, acetic acid and residual ethanol are given versus time (h). As it can be seen in Figure 4A, after a short adaptation time, the ethanol concentration started to decrease and that of acetic acid to increase, and they reached the final concentration of 4.09 and $42.27 \mathrm{~g} / \mathrm{L}$ for residual ethanol and acetic acid, respectively. On the other hand, bacterial biomass concentration increased slightly at the beginning of fermentation, then exponentially after $15 \mathrm{~h}$. Bacterial biomass concentration reached a maximum level of $2.294 \mathrm{~g} / \mathrm{L}$ after $80 \mathrm{~h}$ of fermentation. In the other hand, CV01 strain was investigated for its capacity to withstand thermal stress when switching of the temperature control cooling system (Figure 4B). Such figure shows experimental behavior of tested strain as a comparison with normal conditions given in Figure 4A. As it can be seen, obviously, the temperature started to increase after $20 \mathrm{~h}$ culture when cells have reached the exponential phase. The temperature reached its maximum value $\left(36.47^{\circ} \mathrm{C}\right)$ at the end of exponential phase. Interestingly, despite the increase in temperature, the overall pace of cell growth was not affected. The average values of the final biomass and acetate concentrations were 2.17 and $38.09 \mathrm{~g} / \mathrm{L}$, respectively, slightly lower than those observed in the first optimal experiment. These results agree well with the thermotolerance properties revealed for CV01 bacterium. Consequently, the physiological potentialities of CV01 A. pasteurianus KU710511 could largely be appropriate for a sustainable development of vinegar production in warm countries like Morocco.

\section{Acetous fermentation in 500-L pilot-plan acetifier}

The production of fruit vinegar (apple and date) at a pilot-plant scale was carried out in a 500-L acetator (PASTO GILSON, France). The product of the 6-L lab-scale bioreactor, obtained using the selected CV01 thermotolerant strain, was used as a preculture. Figure 5 shows the evolution of the acetous parameters (produced acetate, residual ethanol, $\mathrm{pH}$, optical density and number of cells) for a semi-continuous fermentation process carried out in a $500 \mathrm{~L}$ acetator for a period of 7 days using alcoholic apple must. After the initial mixing of inoculum and fresh fruit must (time $=0 \mathrm{~h}$ ), no lag phase marked by no significant acid production was observed (Figure 5). This was due to the sudden adaptation of bacterial population to the new environment by synthesizing the required enzymes for substrate degradation. ${ }^{30}$ The raison might be also related to the improvement of the volumetric oxygen transfer coefficient $\left(\mathrm{K}_{\mathrm{L}} \mathrm{a}\right)$ in the bioreactor (better aeration and circulation systems).

The semi-continuous operation of the adopted protocol shown in Figure 1 can be described by the following three mean phases:

- Phase 1: (beginning of the $1^{\text {st }}$ stage): $40 \mathrm{~L}$ of alcoholic fruit must $(E=7.4 \%)$ was inoculated with $6 \mathrm{~L}$ of the preculture taken in its exponential phase obtained from the Lab-scale bioreactor. Water and pure acetic acid were added to arrive at a step volume of $60 \mathrm{~L}(\mathrm{E}=5 \% ; \mathrm{A}=1)$.

- Phase 2: a partial filling-up with a fresh medium $(30 \mathrm{~L}$ and then $60 \mathrm{~L}$ ) is added into the reactor to arrive at a final working volume of $300 \mathrm{~L}$.

- Phase 3: The operation continues in successive stages at a working volume $(300 \mathrm{~L})$ by adding $100 \mathrm{~L}$ of fresh medium and extracting $100 \mathrm{~L}$ of vinegar each time the desired acidity and final ethanol concentration are reached.

In the proposed protocol (see details in material and methods section) it is clearly stated that the main interest lies in achieving values of acetic acid concentration that changes between 10 and 35
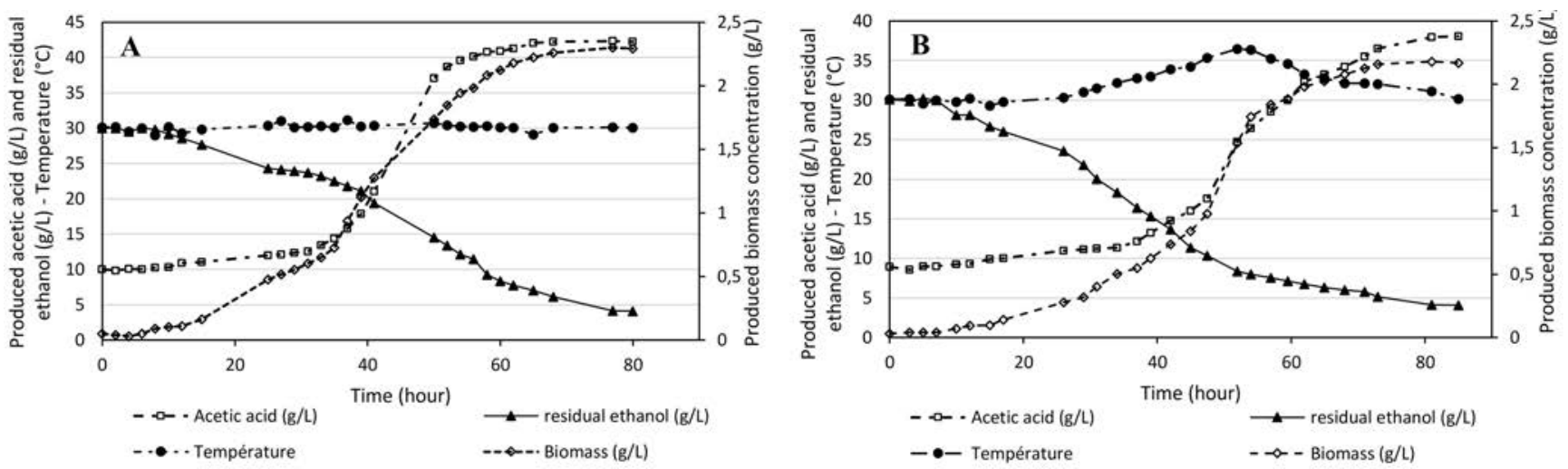

Figure 4. Batch fermentation profile of Acetobacter CV01 strain in a 6-L bioreactor at $30^{\circ} \mathrm{C}(\mathrm{A})$, and at thermal stress condition (B), Cultures were carried out using the optimized culture medium composition. The presented results are the means of two independent replicates. 
$\mathrm{g} / \mathrm{L}$, and ethanol concentrations between 30 and $50 \mathrm{~g} / \mathrm{L}$, an immediate biomass growth with instant formation of fermentation product is observed. The details of the evolution of the concentrations of substrate (ethanol), product (fruit vinegar) and the stoichiometric yield during start-up phase and in every cycle of the semi continuous process are depicted in Table 2. The stoichiometric yields have been calculated as the moles of acetic acid produced per mole of ethanol consumed during the fermentation time.

The results shown in Figure 5 and Table 2 indicate that immediately after inoculation, the CV01 Acetobacter strain begun to grow and oxidize ethanol to acetate. In fact, it is usually stated that Acetobacter strains used in industrial production of vinegar presented a lag phase in the first $h$ and after replacement with fresh wine. ${ }^{4,5}$ The start-up operation lasted about $45 \mathrm{~h}$ and was characterized by a stoichiometric yield of about $80 \%$ and by an instable acetification rate. This can be explained by the change in metabolic pathways of bacteria to adapt to the new environment. ${ }^{30}$ The working volume $(300 \mathrm{~L})$ has been reached by doubling the volume of the last step of the starting operation. This resulted in a significant decrease of the stoichiometric yield. After that, cells entered the exponential growth phase witch has lasted until the end of the second cycle of the semi-continuous fermentation. As it can be seen, there is a high acidic production and a significant decrease of ethanol concentration until the end of the fermentation cycles. The high stoichiometric yield $(100 \%)$ and acetification rate $(0.12 \%)$ have been observed during the second cycle, which corresponds to the log phase of bacterial growth. The progressive increasing of the rate during this phase could be explained by the synthesis of new enzymes from metabolic pathways useful for the fermentation ability. ${ }^{5}$ A stationary phase was observed from the $3^{\text {rd }}$ cycle and a death phase of growth was observed at the middle of the $5^{\text {th }}$ cycle when the high acetic acid concentrations were obtained $[7.3 \%(\mathrm{~m} / \mathrm{v})]$.

In general, it is state of the art that, during acetous fermentation, $1 \% \mathrm{v} / \mathrm{v}$ ethanol allow to obtain $1 \% \mathrm{w} / \mathrm{v}$ acetic acid. ${ }^{31}$ Thus, the observed deviations of calculated yields can be explained by evaporation on substrate or product that can occur during fermentation process. ${ }^{32}$

Finally, the average acetification rate for every cycle, shown in Table 2, expresses the ability of the strain to produce acetic acid during fermentation process. The starting-up protocol and the semi-continuous operation allowed obtaining fruit vinegar with

Table 2. Experimental data of starting-up and semi-continuous fermentation process in $500 \mathrm{~L}$ pilot-plant acetator.

\begin{tabular}{|c|c|c|c|c|c|c|c|c|c|}
\hline \multirow[t]{2}{*}{ Stage } & \multirow[t]{2}{*}{ Duration (h) } & \multicolumn{2}{|c|}{$\begin{array}{l}\text { Acidity \% } \\
\text { (w/v) }\end{array}$} & \multirow[t]{2}{*}{$\begin{array}{l}\text { Produced } \\
\text { acidity \% }\end{array}$} & \multicolumn{2}{|c|}{$\begin{array}{l}\text { Ethanol \% } \\
(\mathrm{w} / \mathrm{v})\end{array}$} & \multirow[t]{2}{*}{$\begin{array}{l}\text { Consumed } \\
\text { ethanol \% }\end{array}$} & \multirow[t]{2}{*}{$\begin{array}{c}\text { Acetification rate } \\
(\% / \mathrm{h})\end{array}$} & \multirow[t]{2}{*}{$\begin{array}{c}\text { Stoichiometric } \\
\text { yield (\%) }\end{array}$} \\
\hline & & Initial & Final & & Initial & Final & & & \\
\hline $60 \mathrm{~L}$ & 19 & 1.1 & 2.8 & 1.7 & 4.95 & 2.8 & 2.15 & 0.09 & 79.07 \\
\hline $90 \mathrm{~L}$ & 18 & 1.9 & 4.7 & 2.8 & 3.55 & 0.1 & 3.45 & 0.16 & 81.16 \\
\hline $150 \mathrm{~L}$ & 9 & 3.75 & 4.2 & 0.45 & 0.8 & 0.2 & 0.6 & 0.05 & 75.0 \\
\hline $300 \mathrm{~L}$ - Cycle 1 & 18 & 4.1 & 5.1 & 1 & 2.5 & 0.25 & 2.25 & 0.06 & 44.44 \\
\hline 300 L - Cycle 2 & 21 & 3.9 & 6.4 & 2.5 & 2.4 & 0.1 & 2.3 & 0.12 & 108.70 \\
\hline $300 \mathrm{~L}$ - Cycle 3 & 10 & 4.53 & 5 & 0.47 & 1.2 & 0.2 & 1 & 0.05 & 47.00 \\
\hline 300 L - Cycle 4 & 17 & 4.8 & 5.7 & 0.9 & 2.3 & 0.3 & 2 & 0.05 & 45.00 \\
\hline 300 L - Cycle 5 & 50 & 5.1 & 7.3 & 2.2 & 2.4 & 0.01 & 2.39 & 0.04 & 92.05 \\
\hline
\end{tabular}

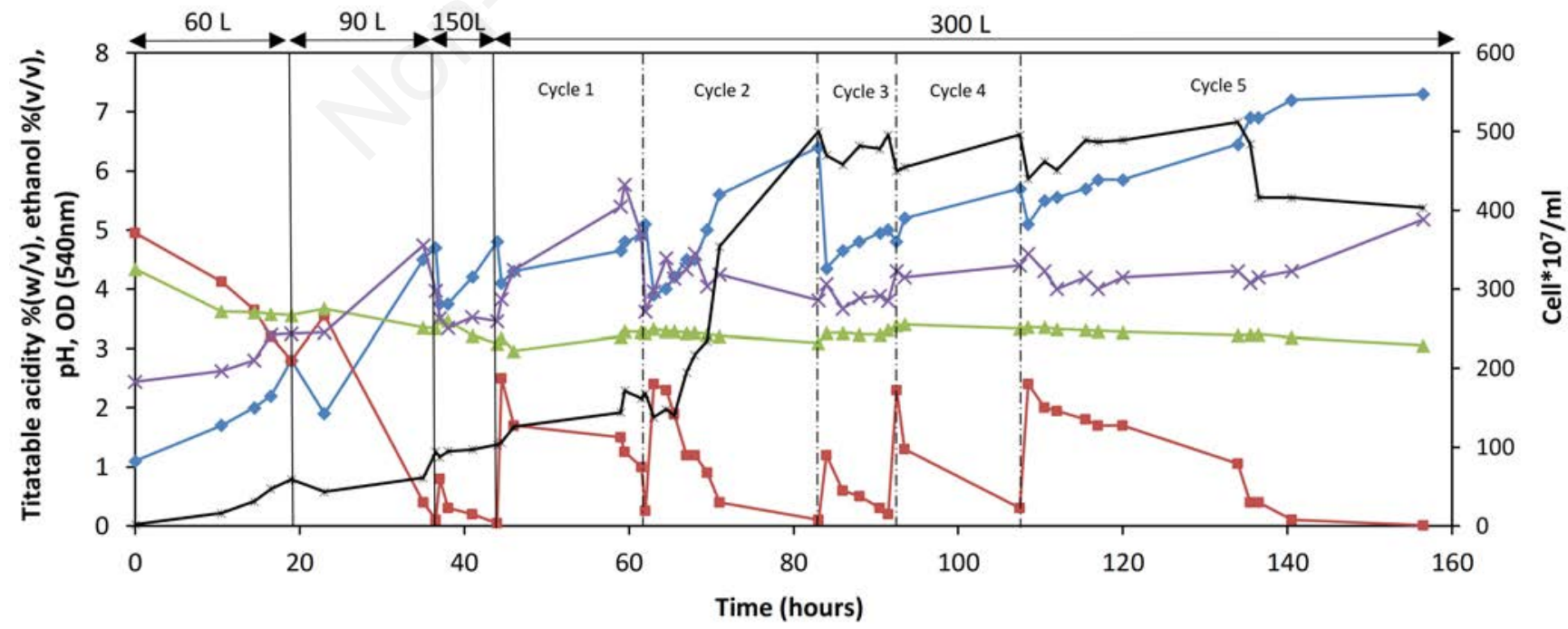

$\multimap$ Titratable acidity $\rightarrow$ Ethanol $\rightarrow \mathrm{pH} \rightarrow$ O.D $(540 \mathrm{~nm})-$ Cell UFC $/ \mathrm{ml}$

Figure 5. Evolution of the acetous fermentation parameters carried out in a $500 \mathrm{~L}$ acetator for a period of 7 days. 
high acetic concentration $(7.3 \%)$ and very low amount of residual ethanol $(0.01 \%)$. Consequently, CV01 A. pasteurianus strain can be useful for the production of fruit vinegar at a large scale.

\section{Aroma profile of produced apple vinegar}

The aromatic compounds of the pilot-plant produced apple vinegar were analyzed using a headspace solid-phase microextraction technique (HS-SPME) along with GC-MS analysis. ${ }^{8}$ The aroma profile of this later was compared to commercial apple vinegar recovered from the local market of Morocco made generally by traditional methods. The aroma of different classes of vinegar was previously evaluated by gas chromatography/mass spectrometry (GC-MS) and gas chromatography/olfactometry (GC-O) to identify substances responsible for aromatic notes associated with the selected descriptors of the typical aroma by Callejón et al..$^{33}$

Tables 3 and 4 illustrate the major aromatic compounds identified from peaks depicted in Figures 6 and 7 by means of masse spectra and retention indices. The general observation that could be stated according to presented data is the remarkable difference in terms of substances responsible for aromatic notes associated to

Table 3. Aroma compounds of pilot plant produced apple vinegar detected by SPME technique.

\begin{tabular}{|c|c|c|c|c|c|c|c|c|c|}
\hline $\begin{array}{l}\text { Peack } \\
\text { num }\end{array}$ & $\begin{array}{c}\text { Concentration } \\
\%\end{array}$ & RT & $\begin{array}{l}\text { AL } \\
(\mathrm{n})^{*}\end{array}$ & $\begin{array}{l}\text { RT } \\
\text { (n) }{ }^{\circ}\end{array}$ & $\begin{array}{l}\text { RT } \\
(\mathrm{n})^{*}\end{array}$ & LRI & Identification & Descriptor & $\begin{array}{l}\text { Identification } \\
\text { basis }\end{array}$ \\
\hline 8 & 3.462 & 2.437 & 9 & 2 & 5.039 & 1314 & Acetic acid & Acidic, vinegar & MS, LRI ${ }^{10}$ \\
\hline 9 & 2.8 & 3.147 & 9 & 2 & 5.039 & 1338 & 2-phenylethanol & $\begin{array}{l}\text { Honey, rose, } \\
\text { spice, lilac }\end{array}$ & MS, LRI ${ }^{37}$ \\
\hline 21 & 1.202 & 9.988 & 11 & 9.683 & 15.2 & 1306 & 2,6-dimethyloctane & ND & $\mathrm{MS}^{\S}$ \\
\hline 27 & 1.228 & 13.752 & 11 & 9.683 & 15.2 & 1374 & Hexadecane, 2,6,10,14-tetramethyl & ND & LRI \\
\hline 30 & 1.303 & 15.458 & 12 & 15.2 & 19.066 & 1307 & Isobutyl alcohol & ND & MS \\
\hline 32 & 0.48 & 15.781 & 12 & 15.2 & 19.066 & 1315 & 1,2-dimethyl-benzene & ND & MS \\
\hline 60 & 20.792 & 22.455 & 13 & 22.215 & 25.1 & 1308 & cis-3-hexenyl acetate & Berry, fruity, sweet & MS, LRI ${ }^{10}$ \\
\hline 66 & 4.566 & 25.177 & 15 & 25.1 & 28.145 & 1303 & Propanoic acid & Vinegar & LRI10 \\
\hline 88 & 2.877 & 29.957 & 16 & 28.145 & 31.308 & 1357 & Octanol & Apple, green, fruity & LRI10 \\
\hline 104 & 2.346 & 34.489 & 17 & 31.308 & 34.554 & 1398 & Benzoic acid & ND & MS \\
\hline 106 & 4.299 & 35.787 & 18 & 34.554 & 37.806 & 1338 & Ethyl 2-hydroxy-3-methylbutanoate & Floral, fruity & MS, LRI ${ }^{10}$ \\
\hline 110 & 4.26 & 37.571 & 18 & 34.554 & 37.806 & 1393 & Methyl octanoate & Fruity & LRI $^{10}$ \\
\hline 115 & 6.415 & 39.297 & 19 & 37.806 & 41.003 & 1347 & 4-vinylguaiacol & Clove, smoky & LRI $^{10}$ \\
\hline 119 & 6.036 & 41.257 & 20 & 41.003 & 44.092 & 1310 & Ethyl heptanoate & ND & MS, LRI \\
\hline 123 & 17.303 & 42.98 & 20 & 41.003 & 44.092 & 1364 & Methyl 3-hydroxy-3-methylbutanoate & Floral, fruity & Pherobase \\
\hline 133 & 8.564 & 45.828 & 21 & 44.092 & 47.105 & 1358 & 2-Propenyl hexanoate & ND & Pherobase \\
\hline 144 & 3.137 & 48.9 & 22 & 47.105 & 50.015 & 1362 & 3-hydroxy-4-phenyl-2-butanone & Floral, clove & MS, LRI \\
\hline
\end{tabular}

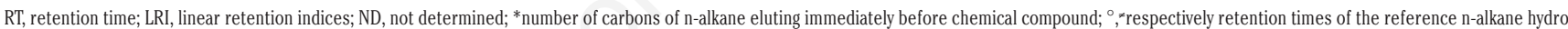
carbons eluting immediately before and after chemical compound; scompounds were identified by masse spectra.

Table 4. Aroma compounds of commercial apple vinegar detected by SPME technique.

\begin{tabular}{|c|c|c|c|c|c|c|c|c|c|}
\hline $\begin{array}{l}\text { Peack } \\
\text { num }\end{array}$ & $\begin{array}{c}\text { Concentration } \\
\%\end{array}$ & RT & $\begin{array}{l}\text { AL } \\
(n)^{*}\end{array}$ & $\begin{array}{l}\text { RT } \\
\text { (n) }\end{array}$ & $\begin{array}{l}\text { RT } \\
(\mathrm{n})^{*}\end{array}$ & LRI & Identification & Descriptor & $\begin{array}{l}\text { Identification } \\
\text { basis }\end{array}$ \\
\hline 4 & 7.427 & 2.624 & 9 & 2 & 5.039 & 1321 & Acetic acid & Acidic, vinegar & MS, LRI \\
\hline 5 & 5.034 & 3.319 & 9 & 2 & 5.039 & 1343 & Ethanol & Wine & $\mathrm{MS}^{\S}$ \\
\hline 20 & 2.954 & 13.234 & 11 & 9.683 & 15.2 & 1364 & 2-Hexanol & Green, grass & $\mathrm{MS}^{37}$ \\
\hline 21 & 4.285 & 15.161 & 11 & 9.683 & 15.2 & 1399 & Iso amyl alcohol & ND & MS, LRI \\
\hline 29 & 1.392 & 18.566 & 12 & 15.2 & 19.066 & 1387 & Dodecamethylcyclohexasiloxane & ND & MS, LRI \\
\hline 35 & 2.62 & 20.522 & 13 & 19.066 & 22.215 & 1346 & 1-Hexanol & Green, grass & $\mathrm{MS}^{37}$ \\
\hline 46 & 11.846 & 23.673 & 14 & 22.215 & 25.1 & 1351 & Butanoic acid & Rancid, cheesy & MS10 \\
\hline 51 & 3.653 & 25.183 & 15 & 25.1 & 28.145 & 1303 & 3-hydroxy-2-butanone & Buttery & MS10 \\
\hline 78 & 2.198 & 34.448 & 16 & 28.145 & 31.308 & 1499 & Hydroxybenzaldehyde & ND & MS, LRI \\
\hline 81 & 5.233 & 35.747 & 17 & 31.308 & 34.554 & 1437 & Hexanoic acid & Sweaty, cheesy & MS10 \\
\hline 82 & 3.907 & 36.497 & 18 & 34.554 & 37.806 & 1360 & Benzyl alcohol & ND & MS, LRI \\
\hline 87 & 9.108 & 37.627 & 18 & 34.554 & 37.806 & 1394 & Benzeneethanol & ND & MS, LRI \\
\hline 107 & 5.795 & 42.537 & 20 & 41.003 & 44.092 & 1350 & Octanoic acid & Sweaty, cheesy & MS, LRI ${ }^{10}$ \\
\hline 114 & 4.492 & 45.733 & 21 & 44.092 & 47.105 & 1354 & Nonanoic acid & Fatty & MS, LRI \\
\hline 125 & 2.048 & 52.908 & 24 & 52.837 & 55.537 & 1303 & 4-vinylphenol & Phenol, smoky & MS, LRI ${ }^{10}$ \\
\hline
\end{tabular}

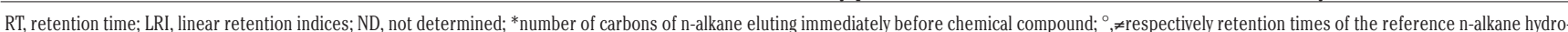
carbons eluting immediately before and after chemical compound; ${ }^{8}$ compounds were identified by masse spectra. 


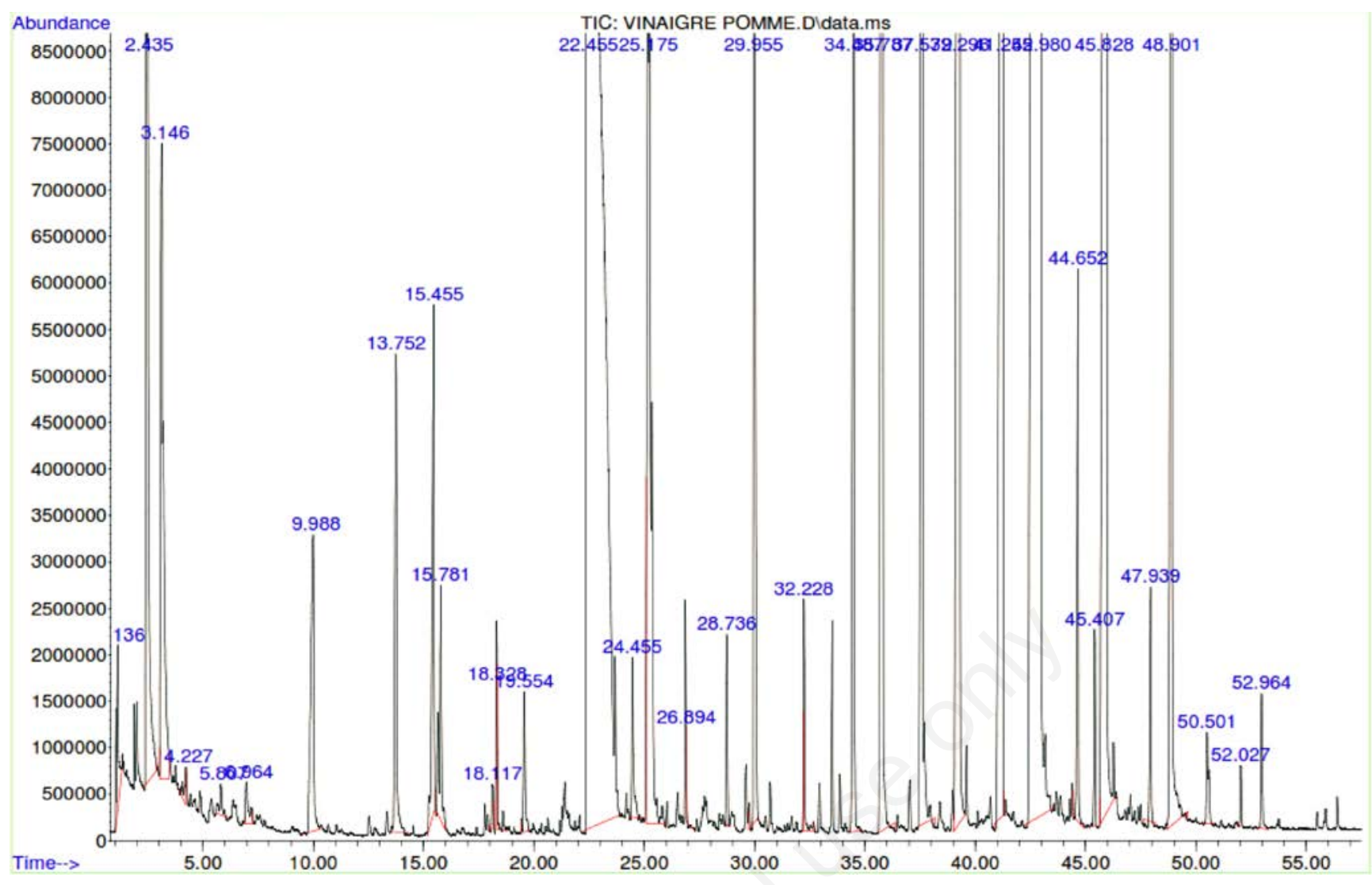

Figure 6. Chromatogram of experimentally produced apple vinegar analyzed by HS-SPME. Identification of peaks according to their retention times are given in Table 3.

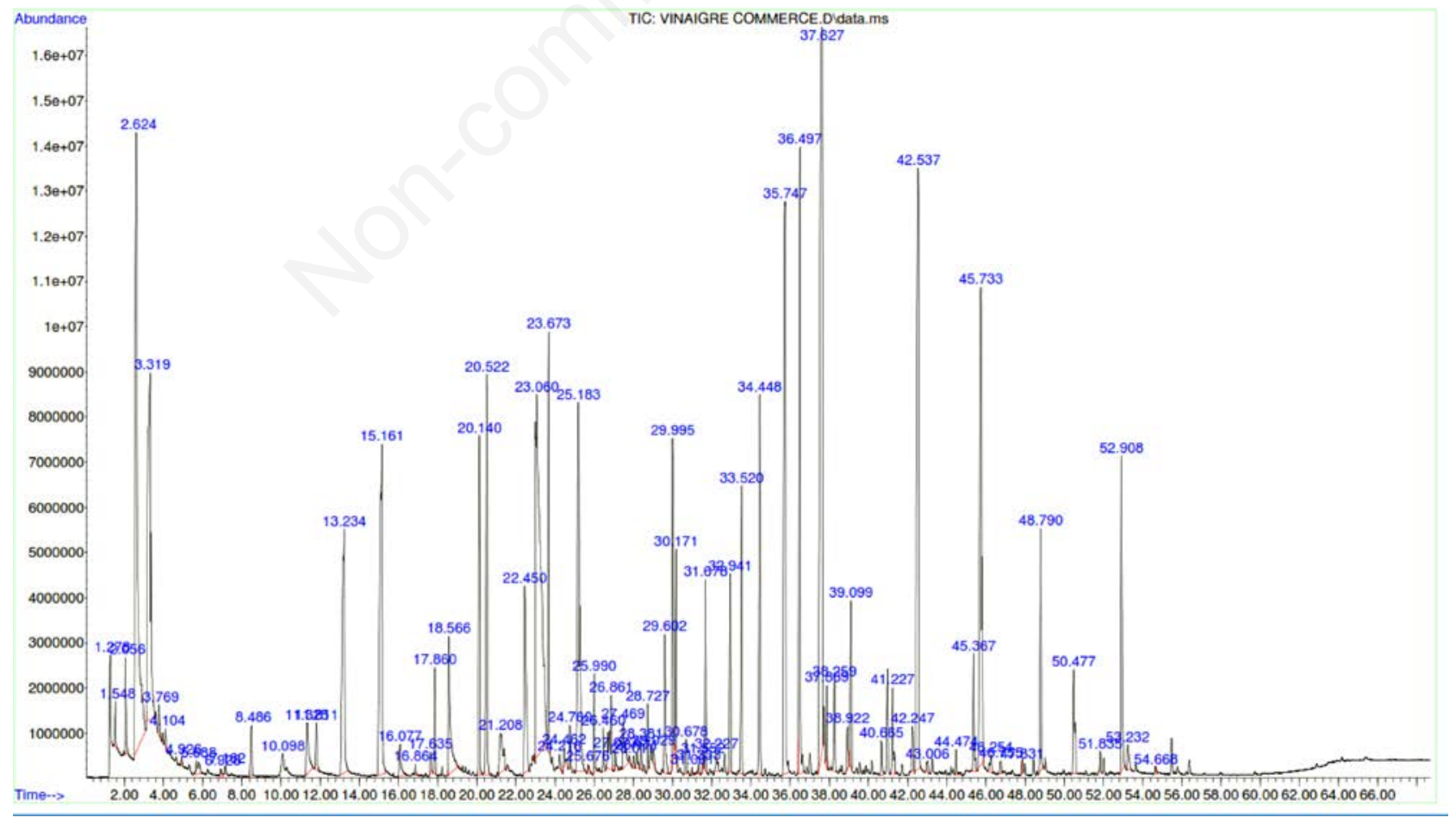

Figure 7. Chromatogram of commercial apple vinegar used as reference. Identification of peaks according to their retention times are given in Table 4. 
each type of analyzed vinegar. On the basis of aroma intensity (concentration \%), Table 3 show that more than $50 \%$ of the aroma profile of the experimental apple vinegar is composed of cis-3hexenyl acetate (20\%), methyl 3-hydroxy-3-methylbutanoate (17\%), 2-Propenyl hexanoate (8.5\%), 4-vinylguaiacol (6.4\%) and ethyl heptanoate $(6 \%)$. The associated aroma descriptors mentioned in the literature of these molecules indicate that they are generally appreciated.

On the other side, the main representative chemicals associated to the commercial apple vinegar aroma are depicted in Table 4. As it can be seen, butanoic acid, benzeneethanol, acetic acid, octanoic acid, hexanoic acid, ethanol and nonanoic acid represent almost $50 \%$ of the aromatic note. Butanoic acid $(11.8 \%)$, octanoic acid and hexanoic acid (11\%) and ethanol (5\%) are associated to rancid, sweaty and wine aroma descriptors, respectively. It was reported that hydroxybenzaldehyde is concentrated during ageing. ${ }^{34}$

The results of HS-SPME of the two kind of vinegar provide compelling evidence in support of a difference in their organoleptic quality. It is evident to state that in addition to the nature of the raw material, fermentation process and microbial species involved in the two stage fermentation of vinegar are the essential factors that determine the final aroma profile. Moreover, it was reported that the ethanol content of vinegars is a factor in the final aromatic richness. ${ }^{35}$

\section{Conclusions}

$\mathrm{AAB}$ are strictly aerobic bacteria that have a long history of use in fermentation processes, and the conversion of ethanol to acetic acid for the production of vinegar is the most well-known application of these bacteria. ${ }^{36,37}$

In this study, a selected thermotolerant $A$. pasteurianus CV01 strain was assessed for its ability to produce and tolerate high amount of acetic acid at high temperatures $\left(38-41^{\circ} \mathrm{C}\right)$ with comparison to other mesophilic and thermotolerant reference strains. Above all, it seems pertinent to remember that this strain could withstand the increase in temperature during acetous fermentation in fermenter. On the other hand, a start-up protocol have been established to perform semi-continuous acetous fermentation in $500-\mathrm{L}$ pilot plant acetator. When interpreting the results, it is important to consider that fermentation operation allowed obtaining a final product with high amount of acetic acid $(7.3 \% \mathrm{w} / \mathrm{v})$ with high acetification rate. Moreover, the aroma profile of the pilot plant produced apple vinegar was compared to commercial one using HS-SPME analysis. The obtained results show richness in well-appreciated aromatic notes recorded for the experimentally produced vinegar. Quantitative analysis of aromatic components and establishment of their correlation with sensory descriptors are to be considered in future studies.

All things considered, it can be concluded that controlled acetous fermentation using selected $\mathrm{AAB}$ strain allowed to produce more profitably a final product with high amount of acetic acid characterized with appreciated aroma profile. CV01 A. pasteurianus strain is then well suited for large-scale production of high quality fruit vinegar in Morocco.

\section{References}

1. Tan SC. Vinegar Fermentation. Thesis, Faculty of the Louisiana State University; 2005. Available from: http://etd.1su.edu/docs/available/etd-11092005-152334/unre-
stricted/Tan thesis.pdf

2. Nanda K, Taniguchi M, Ujike S, Ishihara N, Mori H, Ono H, et al. Characterization of acetic acid bacteria in traditional acetic acid fermentation of rice vinegar (komesu) and unpolished rice vinegar (kurosu) produced in Japan. Appl Env Microbiol. 2001;67:986-90.

3. Kocher GS, Kalra KL, Phutela RP. Comparative Production of Sugarcane Vinegar by Different Immobilization Techniques. J Inst Brew. 2006;112:264-6. Available from: http://onlinelib ra ry.w i 1 e y. com/do i / $10.1002 /$ j. 2050 0416.2006.tb00722.x/abstract

4. de Ory I, Romero LE, Cantero D. Optimum starting-up protocol of a pilot plant scale acetifier for vinegar production. J Food Eng. 2002;52:31-7.

5. Ndoye B, Lebecque S, Destain J, Guiro AT, Thonart P. A new pilot plant scale acetifier designed for vinegar production in Sub-Saharan Africa. Process Biochem. 2007;42:1561-5.

6. Su MS, Chien PJ. Aroma impact components of rabbiteye blueberry (Vaccinium ashei) vinegars. Food Chem [Internet]. 2010;119:923-8. Available from: http://dx.doi.org/10.1016/j.foodchem.2009.07.053

7. Jeong E, Jeon S, Baek J, Cha Y. Volatile Flavor Compounds in Commercial Vinegar Beverages Derived from Fruits. J Life Sci. 2011;21:292-9.

8. Jo D, Kim G-R, Yeo S-H, Jeong Y-J, Noh BS, Kwon J-H. Analysis of aroma compounds of commercial cider vinegars with different acidities using SPME/GC-MS, electronic nose, and sensory evaluation. Food Sci Biotechnol. 2013;22:155965. Available from: http://link.springer.com/10.1007/s10068013-0251-1

9. Ubeda C, Callejón RM, Hidalgo C, Torija MJ, Mas a., Troncoso a. M, et al. Determination of major volatile compounds during the production of fruit vinegars by static headspace gas chromatography-mass spectrometry method. Food Res Int. 2011;44:259-68.

10. Xu Y, Fan W, Qian MC. Characterization of aroma compounds in apple cider using solvent-assisted flavor evaporation and headspace solid-phase microextraction. J Agric Food Chem. 2007;55:3051-7.

11. Del Signore A. Chemometric analysis and volatile compounds of traditional balsamic vinegars from Modena. J Food Eng. 2001;50:77-90.

12. Natera Marìn R, Castro Mejìas R, de Valme Garcìa Moreno M, Garcìa Rowe F, Garcìa Barroso C. Headspace solid-phase microextraction analysis of aroma compounds in vinegar. J Chromatogr A. 2002;967:261-7.

13. Úbeda C, Callejón RM, Troncoso AM, Rojas JM, Peña F, Lourdes Morales M. Impact Odorants in Strawberry Vinegars. In: Ferreira V, Lopez R, editors. Flavour Science. Elsevier Inc.; 2014. p. 177-81.

14. Benkerroum N. Traditional Fermented Foods of North African Countries: Technology and Food Safety Challenges With Regard to Microbiological Risks. Compr Rev Food Sci Food Saf. 2013;12:54-89.

15. Fernández-Cruz ML, Mansilla ML, Tadeo JL. Mycotoxins in fruits and their processed products: Analysis, occurrence and health implications. J Adv Res. 2010;1:113-22.

16. Oukabli A (INRA). Le pommier: une culture de terroir en zones d'altitudes. Transf Technol en Agric. 2004;77-80.

17. Harrak H, Lebrun M, Ismaili Alaoui M, Sarter S, Hamouda A. Biochemical and microbiological phenomena of the medicinal and aromatic plants extract used in the preparation of Tassabount date juice in Morocco. In: Mworia J, editor. Botany. Rijeka: InTech; 2012. p. 85-106. 
18. Shafiei R, Delvigne F, Babanezhad M, Thonart P. Evaluation of viability and growth of Acetobacter senegalensis under different stress conditions. Int J Food Microbiol. 2013;163:20413.

19. Mounir M, Shafiei R, Zarmehrkhorshid R, Hamouda A, Ismaili Alaoui M, Thonart P. Simultaneous production of acetic and gluconic acids by a thermotolerant Acetobacter strain during acetous fermentation in a bioreactor. J Biosci Bioeng. 2016;121:166-71.

20. Mounir M, Shafiei R, Zarmehrkhorshid R, Hamouda A, Thonart $\mathrm{P}$, Delvigne $\mathrm{F}$, et al. Optimization of biomass production of Acetobacter pasteurianus KU710511 as a potential starter for fruit vinegar production. African J Biotechnol. 2016;15:1429-41.

21. Vikas Suman B, Rehana A, Tawheed A. An Overview on the Biological Production of Vinegar. Int J Fermented Foods. 2014;3:139-55.

22. Mounir M, Belgrire M, Lahnaoui S, Hamouda A, Thonart P, Delvigne F, et al. Maîtrise de la fermentation alcoolique sous stress éthanolique, thermique et osmotique de la souche Saccharomyces cerevisiae YSDN1 en vue de la préparation du vinaigre de fruits. Rev Marocaine des Sci Agron Vétérinaires. 2016;4:86-95.

23. Hidalgo C, Mateo E, Cerezo AB, Torija MJ, Mas A. Technological process for production of persimmon and strawberry vinegars. Int J Wine Res. 2010;2:55-61.

24. de Ory I, Romero L, Cantero D. Modelling the kinetics of growth of Acetobacter aceti in discontinuous culture: influence of the temperature of operation. Appl Microbiol Biotechnol. 1998;49:189-93.

25. Nanba A, Tamuru A, Nagai S. Synergistic effect of acetic acid and ethanol on the growth of Acetobacter sp. J Ferment Technol. 1984;62:501-5.

26. Bar R, Gainer JL, Kirwan DJ. An unusual pattern of product inhibition: Batch acetic acid fermentation. Biotechnol Bioeng. 1987;29:796-8.

27. van Den Dool H, Dec. Kratz P. A generalization of the reten- tion index system including linear temperature programmed gas-liquid partition chromatography. J Chromatogr A. 1963;11:463-71.

28. Babushok VI, Linstrom PJ, Zenkevich IG. Retention Indices for Frequently Reported Compounds of Plant Essential Oils. J Phys Chem Ref Data. 2011;40.

29. Harrak H, Boujnah M. Valorisation technologique des dattes au Maroc. 2012th ed. Rabat: Institut National de la Recherche Agronomique; 2012. 1-160 p.

30. Brock TD, Madigan MT. Biology of microorganisms. 6th ed. Englewood Cliffs: NJ: Prentice-Hall; 1991.

31. Adams MR. Vinegar. In: Wood BJB, editor. Microbiology of fermented foods. 2nd ed. New York: Blackie Academic \& Professional; 1998. p. 1-44.

32. De Ory I, Romero LE, Cantero D. Operation in semi-continuous with a closed pilot plant scale acetifier for vinegar production. J Food Eng. 2004;63:39-45.

33. Callejón RM, Morales ML, Silva Ferreira AC, Troncoso AM. Defining the typical aroma of Sherry vinegar: Sensory and chemical approach. J Agric Food Chem. 2008;56:8086-95.

34. Solieri L, Giudici P, editors. Vinegars of the world. 1st ed. CEUR Workshop Proceedings. Mlian: Springer; 2009. 1-305 p.

35. Morales ML, Tesfaye W, García-Parrilla MC, Casas JA, Troncoso AM. Evolution of the Aroma Profile of Sherry Wine Vinegars during an Experimental Aging in Wood. J Agric Food Chem. 2002;50:3173-8.

36. Gullo M, Verzelloni E, Canonico M. Aerobic submerged fermentation by acetic acid bacteria for vinegar production: Process and biotechnological aspects. Process Biochem. 2014;49:1571-9.

37. Budic-Leto I, Zdunic G, Banovic M, Ganic KK, TomicPotrebujes I, Lovric T. Fermentative aroma compounds and sensory descriptors of traditional croatian dessert wine Prošek from Plavac mali cv. Food Technol Biotechnol. 2010;48:530 7. 